\title{
EXPLORING A SOCIAL VULNERABILITY MODEL FOR DISASTER STUDIES: THE CASE OF THE 2011 FLASHFLOOD IN DAVAO CITY, SOUTHERN PHILIPPINES
}

\author{
Karen Joyce G. Cayamanda, PhD \\ University of the Philippines Mindanao \\ e-mail: kgcayamanda@up.edu.ph \\ Mobile number: +639173109898
}

\begin{abstract}
Using the qualitative methods of document analysis and key informant interviews, this paper explored the Berkes \& Ross (2013) framework to show a human-ecological representation in analyzing a disaster situation. The case of the 2011 flashflood in Davao City, Southern Philippines was examined, looking into a social vulnerability model as the focal point of disaster resiliency. Results show that the systems approach on the framework can be an alternative approach to the study of disaster resilience, combining the ecological, psychological and developmental resilience vis-à-vis the role of the institutions and the agencies involved using the community as the central actor for the immediate response to the disaster. Moreover, this analysis showed that the integration of cultural factors can contextualize disaster mitigation. Disaster resiliency at the community levels may be further enhanced using an integrative model with a "participatory bottom-up" approach.
\end{abstract}

Keywords: community resilience, disaster risk reduction, human-ecological dimension, participatory bottom-up approach, social vulnerability model 


\section{Introduction}

Community resilience influences collective ability to respond to disasters and enhancing the resilience of the communities has been a common goal of governments and institutions across the world. However, to fully understand how to enhance community resilience, the literature on social-ecological systems suggest that resilience should be understood as an emergent property of human-environment relationships (Faulkner, Brown and Quinn, 2018). Resilient communities are capable of bouncing back from adverse situations. They can do this by actively influencing and preparing for economic, social and environmental change. When times are bad, they can call upon the myriad of resources that make them a healthy community.

A high level of social capital means that they have access to good information and communication networks in times of difficulty, and can call upon a wide range of resources. For many years there has been an imbalance between the resources invested in disaster response and those dedicated to the prevention and mitigation of disasters. The world community and most individual countries have preferred to tackle the problem by responding to adverse events rather than anticipating them. There are several reasons why this position has become harder and harder to maintain. Mercer (2010) stated that the knowledge of hazards is now substantial at the world scale and increasingly so at the local scale in many parts of the world. Disasters and development are closely linked and that disasters can both destroy development initiatives and create development opportunities as well. Development schemes can both increase and decrease vulnerability.

In addition, the cause and effect relationship between disasters and socio-economic development was ignored. It was observed that disasters were seen in the context of emergency response - not as part of long-term development programming. Development requires institutional and structural transformations of societies to speed up economic growth, reduce levels of inequality and eradicate absolute poverty. Overtime, the effects of disasters can seriously degrade a country's long-term potential for sustained development and cause governments to substantially modify their economic development priorities and programs (Stephenson, 1994). Urbanization is a form of metropolitan growth that is a 
INTERNATIONAL JOURNAL OF EDUCATIONAL MANAGEMENT AND

DEVELOPMENT STUDIES

Volume 1, Issue 1 · September 2020 • ISSN 2719-0633 (PRINT) 2719-0641 (ONLINE)

response to often bewildering sets of economic, social, and political forces and to the physical geography of an area. It is the increase in the population of cities in proportion to the region's rural population. The 20th century is witnessing "the rapid urbanization of the world's population", as the global proportion of urban population rose dramatically from $13 \%$ (220 million) in 1900, to $29 \%$ (732 million) in 1950, to 49\% (3.2 billion) in 2005 and is projected to rise to $60 \%$ (4.9 billion) by 2030 (UN, 2005). Urban ecosystems are the consequence of the intrinsic nature of humans as social beings to live together (Sudhira et al., 2003; Ramachandra and Uttam Kumar, 2012). The process of urbanization contributed by infrastructure initiatives, consequent population growth and migration results in the growth of villages into towns, towns into cities and cities into metros. Urbanization and urban sprawl have posed serious challenges to the decision makers in the city planning and management process involving plethora of issues like infrastructure development, traffic congestion, and basic amenities (electricity, water, and sanitation), etc. (Kulkarni and Ramachandra, 2006).

The Philippines, unlike other countries in Southeast Asia, is not only exposed to tropical storms, but also to many other climate-related hazards especially floods and landslides due to the terrain of the country. This makes the country one of the most vulnerable to climate change. Mindanao, in particular, has experienced a few tropical storms and typhoons in the past and its entry points are usually the northeastern and southeastern parts of Mindanao. In 1970, Typhoon Titang hit the northeastern part of Mindanao, which caused Lake Mainit to overflow while Typhoon Nitang in 1984 struck southeastern Mindanao, killing 1,400 people. However, typhoons and tropical storms of such strength and area span as that of Pablo and Sendong are not common at all in the island. The alarming frequency and magnitude of these natural calamities makes low-lying areas susceptible to flashfloods and its coastal areas vulnerable to tsunamis. Last December 2012, Category 5 Typhoon Pablo devastated a big area of Davao del Sur, Davao del Norte, Davao Oriental and Surigao del Norte while Tropical Storm Sendong afflicted Cagayan de Oro, and majority of Iligan City on December 2011. Davao City, Davao Occidental and Compostela Valley are also prone to these natural calamities resulting in damage to properties, loss of livelihood, and death. One reason for such casualties is that people in the areas affected are not familiar with various precautionary measures to lessen the impact of natural disasters. People living in 


\section{INTERNATIONAL JOURNAL OF EDUCATIONAL MANAGEMENT AND \\ DEVELOPMENT STUDIES}

Volume 1, Issue 1 • September 2020 • ISSN 2719-0633 (PRINT) 2719-0641 (ONLINE)

areas that were not historically known to experience such natural calamities were not prepared for the devastating aftermath (Sanchez \& Sumaylo, 2015).

Davao City (Figure 1) is experiencing unprecedented urbanization and sprawl in recent times due to concentrated developmental activities with impetus on industrialization for the economic development of the region. This concentrated growth has resulted in the increase in population and consequent pressure on infrastructure, natural resources and ultimately giving rise to a plethora of serious challenges such as climate change, enhanced green-house gases emissions, lack of appropriate infrastructure, traffic congestion, and lack of basic amenities (electricity, water, and sanitation) in many localities, etc. As a consequent of this urbanization, flooding has been the most occurring natural event and the frequency of typhoons and storms that pass through the Philippines makes it more vulnerable to flooding (IBRD, 2012; Magalang, 2010).

\section{Figure 1}

Locator map of Davao City, Philippines

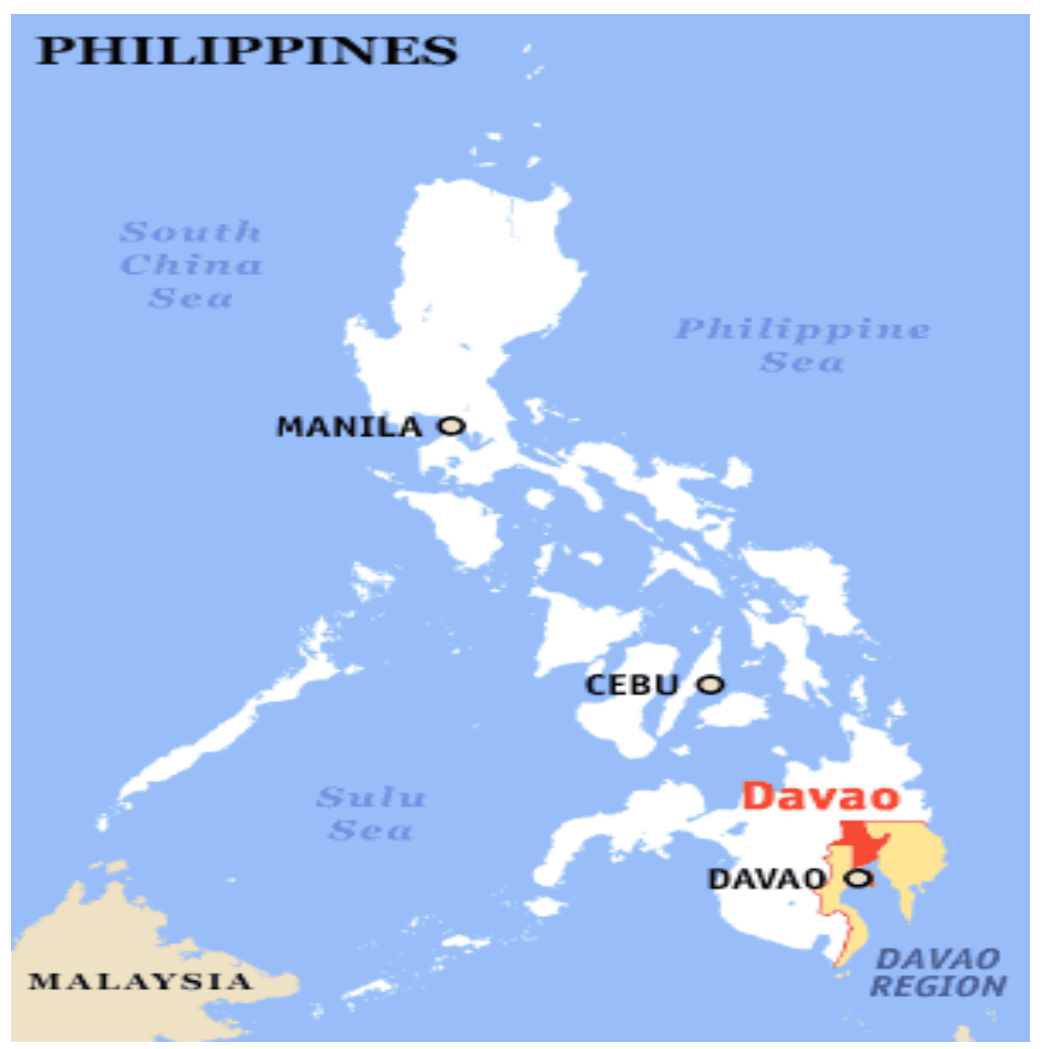


INTERNATIONAL JOURNAL OF EDUCATIONAL MANAGEMENT AND

DEVELOPMENT STUDIES

Volume 1, Issue 1 • September 2020 • ISSN 2719-0633 (PRINT) 2719-0641 (ONLINE)

Figure 2

Disaster Vulnerability of the Area

\begin{tabular}{l|c|c|c|c|c|c|}
\hline \multicolumn{1}{c|}{ Hazard } & Flooding & Drought & $\begin{array}{c}\text { Storm } \\
\text { Surge }\end{array}$ & $\begin{array}{c}\text { Sea-level } \\
\text { Rise }\end{array}$ & Landslide & $\begin{array}{c}\text { Strong } \\
\text { Wind }\end{array}$ \\
\hline \hline Talomo District & & & & & & \\
\hline Bago Aplaya & $\mathrm{X}$ & & & & & \\
\hline Bago Gallera & $\mathrm{X}$ & & & & & \\
\hline Baliok & & & & & & \\
\hline Bucana & $\mathrm{X}$ & & $\mathrm{X}$ & $\mathrm{X}$ & & $\mathrm{X}$ \\
\hline Catalunan Grande & $\mathrm{X}$ & & & & $X$ & \\
\hline Catalunan Pequeño & $\mathrm{X}$ & & & & & $X$ \\
\hline Dumoy & $\mathrm{X}$ & & & & & \\
\hline Langub & & & & & $X$ & \\
\hline Ma-A & $\mathrm{X}$ & & & & $X$ & \\
\hline Magtuod & & & & & $X$ & \\
\hline Matina Aplaya & $\mathrm{X}$ & & & & & \\
\hline Matina Crossing & $\mathrm{X}$ & & & & $X$ & \\
\hline Matina Pangi & $\mathrm{X}$ & & & & $X$ & \\
\hline Talomo & $\mathrm{X}$ & & & & $X$ & \\
\hline$\tau$
\end{tabular}

Source: Volume 3, Sectoral Plan, CLUP 2013-2022

Having an area of 244,000 hectares, Davao City is among the largest cities in the world in terms of area. It may be located in typhoon-free zone, but it is susceptible to flooding in areas adjacent to the City's rivers. Furthermore, Davao river is one of the seven catchments which has the area of about 1,647 square kilometers. Largest waterways drain into the Davao Gulf, particularly Davao and Talomo Rivers considered as most important river basins in the city and pass through heavily populated areas in the city. Hence, thousands of residents are most likely to be affected in case of flooding (Business World Online, 2015). Hence, the disaster vulnerability of some areas in Davao City reflects that majority of the barangays are prone to flooding incidents (Figure 2). Although records will show that flooding and landslides have been a repeated occurrence in Davao City (OCPD; CDRRMO), the flashflood of 2011 has created an impact that shows the need for a policy challenge on the disaster preparedness and response at the community level. Analyzing community resilience as an emergent property of social-ecological systems would help understand the complexities of enhancing resilience of vulnerable communities. Thus, this paper attempts to highlight is the human-ecological aspect as a factor to consider for future disaster risk studies. Specifically, examining the significance of a "bottom-up" approach in building community resilience. 


\section{Literature Review}

\subsection{Climate Change and Disaster Management}

Many of the literature highlights the scientific explanation of disasters being a consequent of climate change (Mochizuki,et al.,2014; O'Brien,et al.,2006; Sanchez, 2014). Climate change has gained unprecedented attention after several natural catastrophes to hit various parts of the world, e.g., earthquakes in Japan and Nepal, tsunami, typhoon Hayan in the Philippines, wildfire in Australia and in Indonesia, Russian drought, Guatemala coffee rust, among others, which has destroyed lives, properties of unimaginable proportion, displaced thousands of people and affected global food supply, etc. (Oxfam International, 2018). The impacts of these changes will depend on the systems in which they occur. Climate change, although a natural phenomenon is accelerated by human activities. Disaster policy response to climate change is dependent on a number of factors, such as readiness to accept the reality of climate change, institutions and capacity, as well as willingness to embed climate change risk assessment and management in development strategies (Cadag \& Gaillard, 2012; Mercado, 2016; Mochizuki, et al., 2014). These conditions do not yet exist universally (O’Brien, et al., 2006).

In the previous decades, we have considered disasters as generally natural phenomenon and that it was part of nature's reaction to climate and weather situations (Doods, 2015; Furedi, 2007). However, through the years, we have come to realize that disasters are becoming closely correlated with human activities. In fact, studies have shown that some of the most harmful disasters are caused by human activities (Gall, 2013; Habito, 2009).

Some literatures on disaster and climate change have shown that disasters have been a consequence of inevitable events that are done by nature or by actions of humans (Mochizuki, et al., 2014; Olson, 2010; Ramachandra, Kumar and Aithal, 2012). In the current situation where the main characters of disaster are massive population growth, intense urbanization and uneven development, disaster assessment and management become an integral part of the planning and development concerns (Olson, 2010; UNISDR, 2013; World Development Report, 2015). There is a close correlation between increased demographic pressure, especially in developing countries (most notably in less developed countries), 
INTERNATIONAL JOURNAL OF EDUCATIONAL MANAGEMENT AND

DEVELOPMENT STUDIES

Volume 1, Issue 1 · September 2020 • ISSN 2719-0633 (PRINT) 2719-0641 (ONLINE)

growing environmental degradation, increased human vulnerability and the intensity of the impact of disasters. Detrimental development and inappropriate use of resources are contributory factors to natural disasters. They can accelerate or amplify recurrent phenomena such as droughts. Environmental degradation increases the intensity of natural hazards and is often the factor that transforms the hazard, or a climatic condition such as heavy downpour into a disaster --- thus, river and lake floods are aggravated by deforestation which in turn causes erosion and clogs rivers (UNISDR, 2013; UN, 2001; O’Brien, et al., 2006).

Disaster Management is a collective term encompassing all aspects of planning for and responding to disasters, including both pre and post disaster activities. It refers to the management of both the risks and consequences of disaster (UNDP, 1991). Thus, there is a need to approach the issue on a holistic approach, whereby, four areas of concerns must be addressed: disaster prevention \& mitigation and disaster preparedness for the pre-disaster stage; while disaster response and disaster rehabilitation and recovery for post disaster stage (NDRRMP). The Philippines approach in responding to climate change and disaster has been an attempt to integrate all the efforts of different agencies and build on the premise that vulnerability, hazards and capacity-building have been explored and studied. The Disaster Management approach addresses the Millennium Goal Section IV, Protecting our common environment: "To intensify collective efforts to reduce the number and effects of natural and man-made disasters (UN, 2001). However, after 15 years, the MDG report revealed that one of the issues still needed closer attention is the climate change and environmental degradation that undermine progress and that the poor people suffer the most. Thus, there is an urgent need for disaster management to be further enhanced and carefully planned. In so doing, whether the disaster is caused by environmental, climatic, biological, technological, geological, industrial or accident-related activities --- the new approach calls for capacitybuilding and resilience (Samadar, et al., 2015).

In the cases of some communities in the Philippines, disaster resilient communities and capacity-building initiatives have been introduced to address vulnerability reduction and social protection that may eventually lead to sustainable development. The state of the community's capacity to face and overcome disasters is deeply affected by its physical/environmental, economic, socio-cultural and political contexts --- these factors 
INTERNATIONAL JOURNAL OF EDUCATIONAL MANAGEMENT AND

DEVELOPMENT STUDIES

Volume 1, Issue 1 • September 2020 • ISSN 2719-0633 (PRINT) 2719-0641 (ONLINE)

ultimately translate into environmental degradation, people's access and control on different forms of resources and assets, inequality that led to exclusion of women, children, elderly and minority groups --- all contribute significantly to shaping a community's level of resiliency or vulnerability to disaster risks (dela Cruz, Ferrer \& Pagaduan, 2010).

\subsection{The Role of the Communities to Reduce vulnerability}

The reality that disasters, especially those induced by climate change, will be more frequent and ferocious in this and the succeeding generations, thus, requires the steadfast effort in finding new solutions and promoting proven strategies to mitigate if not prevent damaging impacts. This task is more urgent because it is the poor majority who is at most risk to these disasters, yet the least prepared and least able to cope with its consequences (Villanueva and Aid, 2010). Resilience, thus, is becoming influential in development and vulnerability reduction sectors such as social protection, disaster risk reduction and climate change adaptation. Policy makers, donors and international development agencies are now increasingly referring to the term (Bene, et al., 2012). Some of the literature reveals that there is a link between resilience and reducing vulnerability (Badri, 2006; Gall, 2013; Bene, et al.,2012; David, 2010; Garcia, 2010; Balang, 2010). The higher the resilience, the higher is the reduction of vulnerability. The Cuban model of resilience sheds light on the variables that create systemic resilience in the built environment and its relations with the social and natural environment (Lizarralde, et al., 2015). Similarly, building disaster-resilient communities (Badri, 2006; Balang, 2010) have been initiated in some areas in the Philippines that aimed to reduce community vulnerabilities to disasters by incorporating DRR into their community development programs (David, 2010). The pilot projects documented include: early warning system (Garcia, 2010), vulnerability reduction \& social protection and participatory disaster-responsive governance (Dela Cruz, Ferrer and Pagaduan, 2010).

Similarly, building disaster-resilient communities to reduce vulnerability proves to be effective using the community-participatory approach (Cadag \& Gaillard, 2012; Tselios and Tompkins, 2017). Some of the documented initial projects in the Philippines have shown that the more involved are the community and stakeholders, the higher is the assurance of effectiveness (Garcia, 2010; David, et al, 2009; Magalang, 2005; Balang, 2010). 


\subsection{Basic Models of Disaster Risk Studies}

\section{A. Disaster Risk Management Models}

Khan, Vasilesco \& A. Khan (2008) discussed that Disaster Risk Management includes sum total of all activities, programs and measures which can be taken up before, during and after a disaster with the purpose to avoid a disaster, reduce its impact or recover from its losses. The three key stages of activities that are taken up within disaster risk management (Fig. 3) are as follows: Pre-disaster phase is before a disaster. Pre-disaster activities those that are taken to reduce human and property losses caused by a potential hazard. For example, carrying out awareness campaigns, strengthening the existing weak structures, preparation of the disaster management plans at household and community level, etc. Such risk reduction measures taken under this stage are termed as mitigation and preparedness activities. Disaster occurrence is during a disaster. These include initiatives taken to ensure that the needs and provisions of victims are met and suffering is minimized. Activities taken under this stage are called emergency response activities. Post disaster is after a disaster. There are initiatives taken in response to a disaster with a purpose to achieve early recovery and rehabilitation of affected communities, immediately after a disaster strike. These are called as response and recovery activities.

\section{Figure 3}

Disaster Management

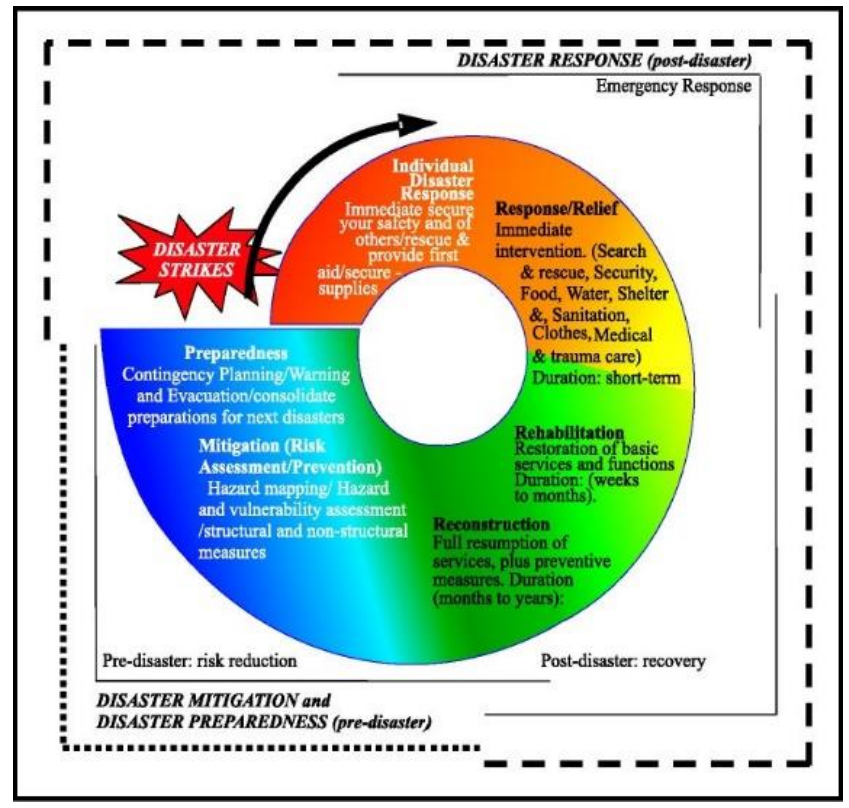




\section{Figure 4}

Disaster Management Cycle

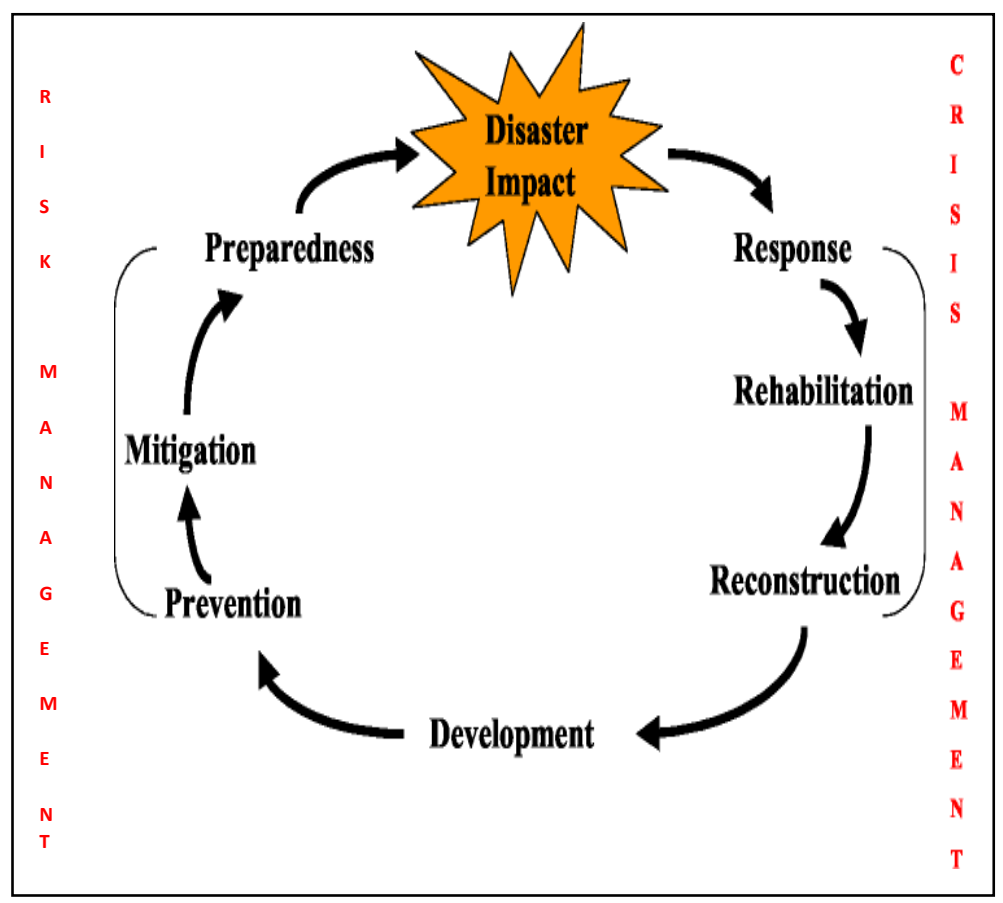

The Disaster Risk Management Cycle (DRMC) diagram (Figure 4) highlights the range of initiatives that normally occur during both the Emergency response and Recovery stages of a disaster. Some of this cut across both stages (such things as coordination and the provision of ongoing assistance); while other activities are unique to each stage (e.g. Early Warning and Evacuation during Emergency Response; and Reconstruction and Economic and Social Recovery as part of Recovery). The DRMC also highlights the role of the media, where there is a strong relationship between this and funding opportunities. This diagram works best for relatively sudden-onset disasters, such as floods, earthquakes, bushfires, tsunamis, cyclones etc, but is less reflective of slow-onset disasters, such as drought, where there is no obviously recognizable single event that triggers the movement into the Emergency Response stage. In all the stages of the cycle, communication plays a vital role at different levels and with specific objectives.

\section{B. Crunch Model of Disaster}

Systems or processes aims to simplify specific problem by isolating the major influencing factors (although at the expense of other factors). By so doing, they aim to enable 
INTERNATIONAL JOURNAL OF EDUCATIONAL MANAGEMENT AND

DEVELOPMENT STUDIES

Volume 1, Issue 1 · September 2020 • ISSN 2719-0633 (PRINT) 2719-0641 (ONLINE)

their users to predict how systems or processes will behave as those pre-selected criteria alter. They are limited as they do not fully represent reality, and their effectiveness degrades as social phenomena are included, however, they are helpful in guiding understanding.

- "unsafe conditions" may be: poor housing conditions, dangerous location, risky livelihoods, lack of disaster preparedness skills, etc.

- "dynamic pressures" may be: no community organization for collective efforts to reduce flood risks, rapid migration tendencies that change the social structure, the lack of local markets for small farmers to sell their produces or buy agricultural inputs, etc.

- "root causes" may be: government negligence of sand mining in that river, the lack of government policy on flood warning systems and land use planning, poor men and women are not allowed to attend meetings on flood mitigation and emergency response preparedness, etc.

\section{Figure 5}

The Crunch Model

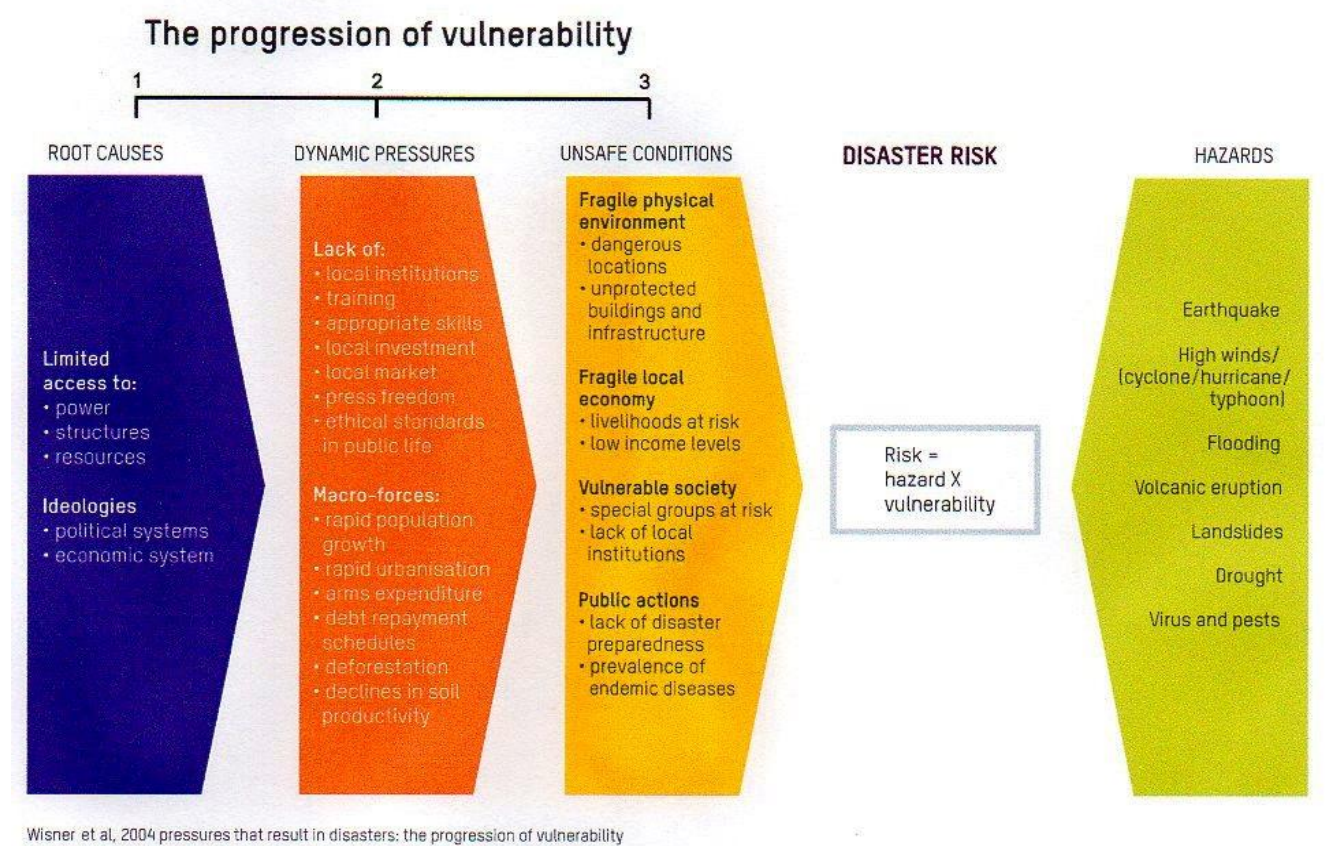

The models of disaster risk studies have been effective in identifying the stages in the cycle of disaster management, clearly identifying the steps of the cycle and explaining the 
INTERNATIONAL JOURNAL OF EDUCATIONAL MANAGEMENT AND

DEVELOPMENT STUDIES

Volume 1, Issue 1 • September 2020 • ISSN 2719-0633 (PRINT) 2719-0641 (ONLINE)

factors that lead to the progression of vulnerabilities of a community. However, there is minimal focus on how communities can build their resilience using the social and ecological component of the community. The models may have been useful in analyzing and examining the 2011 Davao City flash flood, however, results of the case studies seem to capitalize more on the scientific and technical elements of the disaster and risk studies. A few studies on modelling risk communication have emphasized the role of transforming concepts into frameworks that are easier to operationalize during disaster events (O’Neill, 2014; Reynolds \& Seeger, 2005; Demeritt \& Nobert, 2014). However, the emphasis focused on the dynamics of the communication processes and the interplay of the elements of the communication.

\section{The Community Resilience Framework}

Resilience - and its complement of achieving transformation to more desirable systems - is an appropriate goal in attempting to manage the complex problems of human and environmental change. Various strand of thoughts cut across the interdisciplinary fields such as ecosystem behaviors, human dimensions and disaster studies. Integrating these can provide a shift in the social-ecological systems. Community action can contribute to this reconciliation. Each of these strands of resilience thinking is relevant to an understanding of 'community resilience': a term often used in both policy and activism. Meanwhile, disaster resilience combines ideas from the psychology and mental health literature (but more focused on individuals and households). The social-ecological systems (including the economic), but developing a far more sophisticated understanding of the many ways in which the human dimensions drive their ecosystems and adapt to change. Social change through activism, and understanding and addressing power relationships in the process, is a crucial but hitherto neglected area. Figure 6 shows that Berkes and Ross (2013) listed a number of elements that have been identified in research and noted that agency and self-organizing are needed to convert latent strengths into active processes when required.

The Systems Theory exemplified by this model captures all the elements highlighted in community resilience framework, such as the integral actors involved, specifically, looking at the roles of the environment, institutions and the human capital as a whole. Using a specific case of disaster as a focal point of the analysis aims to highlight a socio-ecological impact of disaster relating it to the very significant role played by the 
INTERNATIONAL JOURNAL OF EDUCATIONAL MANAGEMENT AND

DEVELOPMENT STUDIES

Volume 1, Issue 1 · September 2020 • ISSN 2719-0633 (PRINT) 2719-0641 (ONLINE)

institutions. The case of the 2011 flashflood was examined highlighting the elements of the community resilience framework (Figure 6). Some studies on social-ecological frameworks have been used to look into evaluation of green infrastructure for DRR (Cowles, 2015), promotion of sustainable and resilient communities (Ramolini, Bixler \& Grove, 2016), suicide prevention (Cramer \& Kapusta, 2017) and measuring disaster recovery (Abramson, et al., 2010). Although these studies have focused on social vulnerability, there was no single approach or mechanism in the development of the frameworks. Factors and elements have been considered depending on the context of the studies.

\section{Figure 6}

Community resilience framework by Berkes \& Ross (2013)

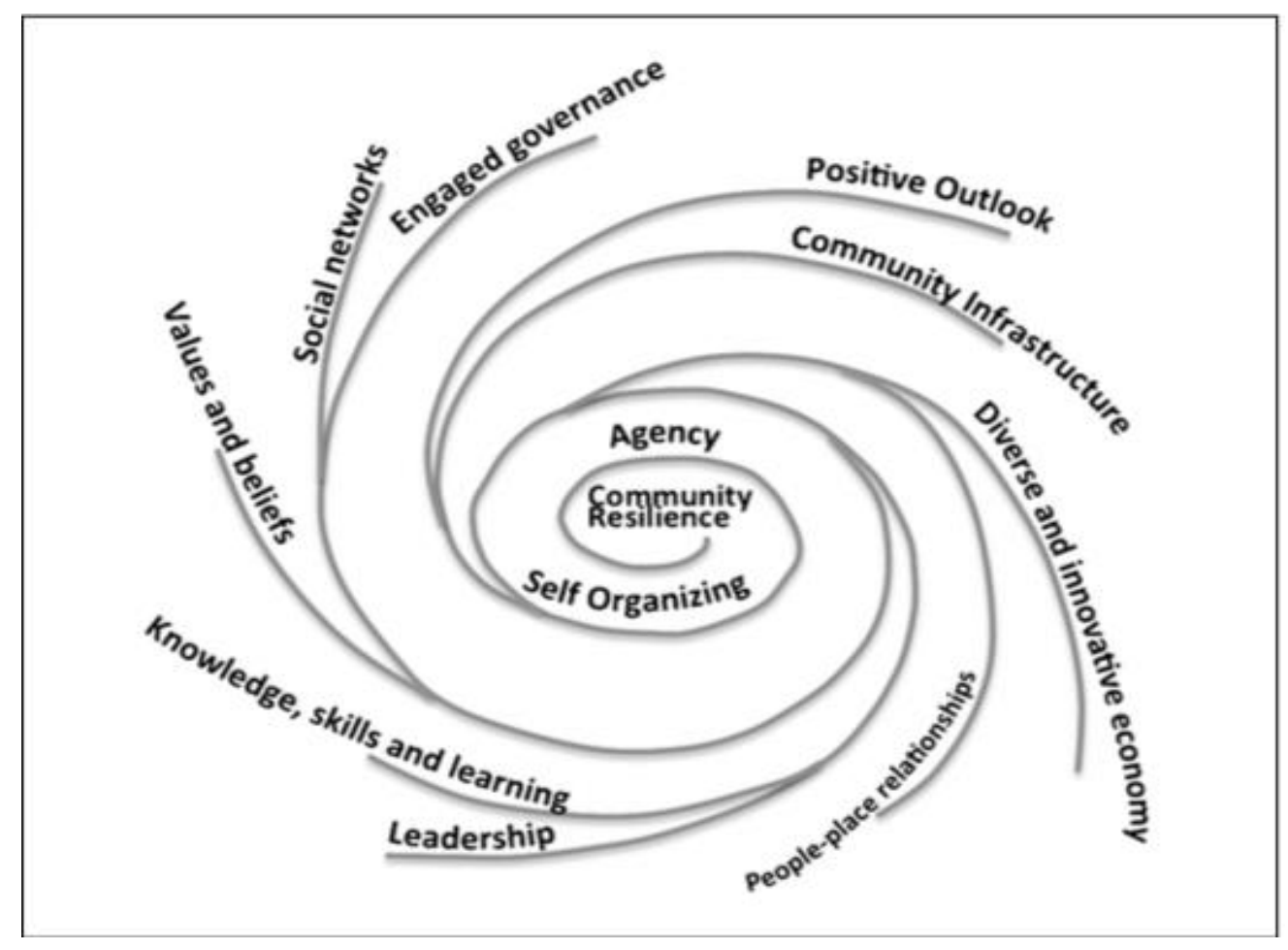

Thus, there is notable flexibility in social-ecological models that may accommodate the integration of appropriate elements on disaster resiliency at the community level. This paper attempts to exemplify that social-ecological frameworks may provide a community-based approach on resilient studies that covers an integration of the interdisciplinary and intercultural elements on disaster resiliency. The model suggests that community action could be focused on building adaptive capacity, focusing on the sets of strengths known to contribute to adaptive capacity, and communities' senses of agency and capability for self- 
INTERNATIONAL JOURNAL OF EDUCATIONAL MANAGEMENT AND

DEVELOPMENT STUDIES

Volume 1, Issue 1 • September 2020 • ISSN 2719-0633 (PRINT) 2719-0641 (ONLINE)

organizing. Like the social-ecological systems theorists and activists, understanding resilience as a multi-level phenomenon, in which local links readily to global, and the resilience of individuals contributes to and receives from the resilience of their communities and places. Two major opportunities for community action would involve the community developers and community actors. Community developers, taking a resilience perspective, have a clear role in building and integrating selected community strengths, and empowering communities to self-organize and exert agency in order to build the resilience of the local parts of the global system they steward. Community actors, and activists, can adopt a resilience perspective to reshape their social and ecological goals: from past and current goals towards improving the world and local places, to building the resilience of their parts of the globe (and global systems such as energy use) to both known and as yet unknown threats and challenges. Successful action often links local action with global networks, producing the cross-scale effects and multi-level change phenomena recognized by social-ecological systems theorists.

\section{Methodology}

This paper reflects the Case Study on the 2011 flashflood in Davao City and attempts to highlight the human-ecological aspect as a factor to consider for future disaster risk studies. Specifically, examining the significance of a "bottom-up" approach in building community resilience. Using the qualitative methods of document analysis and key informant interviews, the Berkes \& Ross (2013) framework was utilized to show a human-ecological representation in analyzing a disaster situation.

\subsection{Data Gathering Process}

The qualitative method of the study employed the document analysis utilizing data from the National Disaster Risk and Reduction Management Plan (NDRRMP), and reports from the Davao City Disaster Risk and Reduction Management Office (NDRRMO), Office of the City Planning and Development (OCPD), National Disaster Risk and Management Council (NDRMC). The Key Informant Interviews (KII) were done among the key personnel from the agencies responsible for the disaster-related incidents, specifically, the DRRMO, the Public Safety and Security Command Center (PSSCC) and the President of the Association of Barangay Captains (LIGA-ABC). The data generation consisted of quotations from the 
INTERNATIONAL JOURNAL OF EDUCATIONAL MANAGEMENT AND

DEVELOPMENT STUDIES

Volume 1, Issue 1 • September 2020 • ISSN 2719-0633 (PRINT) 2719-0641 (ONLINE)

narratives documented through key informant interviews reinforced by focus group discussions from selected residents of the affected areas utilizing a semi-structured interview approach. List of questions have been prepared to ensure that the same basic lines of inquiry are asked from all informants, but the researcher has the flexibility (Cacho, 2014) to modify and explore, probe or build further conversations for clarification and illumination purposes. Using the secondary and primary data from key informant interviews and focus group discussions, policy and content analysis were used. Consequently, ethical considerations were observed through an Informed Consent Form, giving the participants the objectives of the study and how the data will be used for this study.

\subsection{Method of Analysis}

The analytical framework used for the study was the Community Resilience Framework by Berkes and Ross (2013). The model represents the ecological resilience school of thought, developed as a "hurricane shaped" framework (Figure 4) reflecting the interplay of factors involved in community resilience. The framework combines ecological resilience with psychological and developmental resilience. It also includes people-place connections, such as social and economic assets, while maintaining aspects of non-linearity, renewal cycles, scale and more. This appears to be a first step towards integrating ecological and disaster resilience.

Using this lens as a framework for the discussion and analysis on the case of the 2011

Davao City flashflood aims to show the inter-relationships of all the elements involved in the disaster response, post-disaster actions that will serve as mitigation strategies in case of another incident, and the disaster risk reduction strategies using the community as the central actor for the immediate reaction to the disaster.

\section{Results and Discussion}

Considered as one of the largest cities in the world with an area of 244,000 hectares, Davao City's area constitutes $8 \%$ of the land area of the Southern Mindanao Region. Its location outside the typhoon belt makes Davao City as the fruit basket in the Philippines. The entire land area of Davao City primarily drains itself towards the Gulf Davao River and Talomo River, considered as the two most important river basins in the city. Consequently, 
INTERNATIONAL JOURNAL OF EDUCATIONAL MANAGEMENT AND

DEVELOPMENT STUDIES

Volume 1, Issue 1 · September 2020 • ISSN 2719-0633 (PRINT) 2719-0641 (ONLINE)

the Davao City river is one of the seven catchments or river basins which has the largest catchment area of about 1,647 square kilometers. Along with this basin is its sub-basin, the Matina River basin. Despite the fact that Davao City is considered as a typhoon-free city, it has not been spared of the devastating flashflood that happened on June 28, 2011 (Estacio, 2013; Sanchez \& Sumaylo, 2015).

\subsection{A Narrative of the Disaster Response}

On June 28, 2011, the Philippine Atmospheric, Geophysical and Astronomical Services Administration (PAG-ASA) identified an Inter-Topical Convergence Zone was present in the southern part of Mindanao and this ITCZ was caused by the convergence of two trade winds-nor east trade winds and southeast trade winds in a particular area. The convergence of these winds resulted to thunderstorm clouds in the uplands of Tugbok District where the Pangi River originates along with Calinan and Talomo that generated heavy rain for about three hours. The heavy pouring of rain resulted to the overflowing of the Pangi River, which brought a destructive flashflood to riverside communities. The flashflood incident left a total of 8,464 affected families in 34 areas, with 29 casualties due to drowning despite the immediacy of response and action of the different agencies and concerned organizations. In the previous years, barangay Matina experienced a couple of flooding in these areas, however, the June 2011 flashflood was an unexpected disaster that resulted to loss of lives and damage to properties.

At the onset of the flashflood, the response team of the barangay and other agencies were not able to penetrate immediately the affected areas due to the forceful and risky current and height of the floodwaters. It was only when the water started to subside that responders were able to reach the affected areas. Using Berkes lens, the previous experience with flooding has provided the community the knowledge, skills and learning that would be useful for future exposure to the same incident if this will again occur in the future.

Various concerned agencies, private organizations and NGOs, in addition to the government agencies were responders of the disaster. The incident revealed a strong sense of social capital exhibited by the magnitude of responders that arrived from the onset of the disaster and evacuation and recovery was initiated on the first six hours (NDRRMC, 2011). 


\section{INTERNATIONAL JOURNAL OF EDUCATIONAL MANAGEMENT AND DEVELOPMENT STUDIES}

Volume 1, Issue $1 \cdot$ September 2020 • ISSN 2719-0633 (PRINT) 2719-0641 (ONLINE)

However, despite the efforts and the preparedness level among the concerned agencies and sectors, initial post disaster studies on the flashflood incident revealed that there is a low awareness and level of risk perception among the communities. Further, there was a lack of communication protocols that led to the negative impact of the disaster incident (Estacio,2013; Sanchez, 2014; Sanchez\&Sumaylo,2015). Hence, the gap of six hours before the initial response arrived may have a great impact if the community is aware on how they can perceive the risk level they are facing (Mercado, 2016).

Coupled systems of humans and nature are complex, in terms of how they anticipate and respond to natural disasters. These complexities present great uncertainties for many facets of society. The capacity to deal with the types of uncertainty and surprises will require novel approaches, creative combinations of strategies, and the ability to adapt in a changing environment. Accelerating learning and supporting novel approaches that limit vulnerability and expand our understanding of the occurrence and impacts of natural disasters seem to be critical components of building community resilience.

\subsection{The Community Infrastructure}

Barangay Matina Crossing 74-A (Figure 7) is situated in the Southwest portion of Davao City with a total land area of 568 hectares. It has a flat topography stretching towards the Davao Gulf. Sixty percent (60\%) of its land area is residential, thirty-nine (39\%) is composed of commercial and light industries and about one percent is used for agricultural purposes. It covers sixty-three (63) puroks under its jurisdiction, which makes it one of the biggest barangays in the 1st Congressional District of Davao City (Sanchez, 2014).

\section{Figure 7}

\section{Geographic location of the Study}
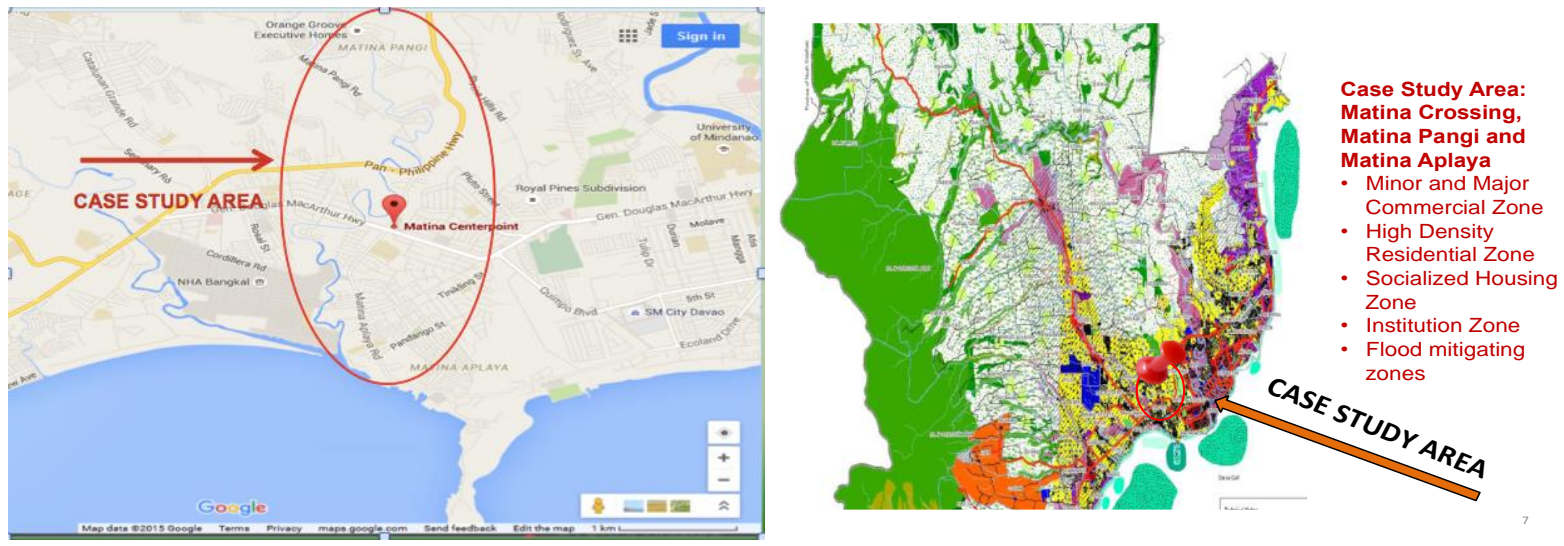
INTERNATIONAL JOURNAL OF EDUCATIONAL MANAGEMENT AND

DEVELOPMENT STUDIES

Volume 1, Issue 1 • September 2020 • ISSN 2719-0633 (PRINT) 2719-0641 (ONLINE)

However, it is also considered a flood risk area with flood mitigating zones were two major rivers run along the several barangays in Matina, namely : Pangi River (which cuts across Purok Sambag, San Isidro, Guadalupe, Mahayahay, Arroyo compound, Balusong, Lopez Village, Alzate compound, Concepcion compound and Doña Francisco) and Davao River which sets the boundary of the two puroks in Matina Gravahan. As recorded by the Barangay Office, the puroks enumerated above were inundated by the overbanking of the two rivers situated near them for the past years. Similarly, it is considered as an urban area.

Table 1 shows the locale of this analysis which includes the communities living in Matina Crossing, Matina Pangi and Matina Aplaya. The area consisted of both minor and major commercial zones characterized by presence of small, medium and large commercial establishments. Further, institutions like banks, schools, groceries and public markets are found in the area. It is a high-density residential zone with a socialized housing zone.

Table 1

Population Distribution of Matina, Davao City

\begin{tabular}{cccccc}
\hline Barangay & $\begin{array}{c}\text { Household } \\
\text { Population }\end{array}$ & $\begin{array}{c}\text { Number of } \\
\text { Household }\end{array}$ & $\begin{array}{c}\text { Average } \\
\text { Household } \\
\text { Size }\end{array}$ & $\begin{array}{c}\text { Population } \\
\text { Density }\end{array}$ & $\begin{array}{c}\text { Built Up } \\
\text { Density }\end{array}$ \\
\hline $\begin{array}{c}\text { Matina } \\
\text { Aplaya }\end{array}$ & 29,619 & 8,022 & 4.2 & 96.67 & 1.23 \\
$\begin{array}{c}\text { Matina } \\
\text { Crossing }\end{array}$ & 34,003 & 3,083 & 4.2 & 64.55 & 0.70 \\
$\quad \begin{array}{l}\text { Matina } \\
\text { Pangi }\end{array}$ & 13,625 & 13,545 & 4.3 & 21.24 & 1.13 \\
\hline \multicolumn{2}{c}{ Classified as Urban area by the OCPD, Davao as per guidelines of the National Statistics Office }
\end{tabular}

The community infrastructure presents the pre-disaster situation of the flashflood incident, describing the elements that may be affected by a disaster and how these elements respond to a natural disaster. Similarly, the community as an urban area shows the interplay of the people-place relationships with a diverse, innovative economy. Moreover, records show that barangay Matina experienced a couple of flooding in these areas even in the previous years. The previous experience with flooding provides the community and its residents with the knowledge, skills and learning that make them confident to respond to the 
INTERNATIONAL JOURNAL OF EDUCATIONAL MANAGEMENT AND

DEVELOPMENT STUDIES

Volume 1, Issue 1 • September 2020 • ISSN 2719-0633 (PRINT) 2719-0641 (ONLINE)

flooding incident. However, the June 2011 flashflood was an unexpected disaster that resulted to loss of lives and damage to properties.

\subsection{The Role of the different Institutions in the Response Measures}

This part of the analysis covers the role of leadership and engaged governance that gave the community the empowerment and support to attain its resiliency on the disaster.

Recovery and Response. The immediacy of response and action of the different agencies and concerned organizations to assist the affected areas initially started six hours after the disaster.

- June 28, 2011 - within the first 6 hours of the disaster, massive relocation efforts were done to put victims on safer grounds (2nd and 3rd floors of the Barangay Hall)

- first-aid teams immediately addressed medical concerns of the victims once settled in the relocation site

- June 29, 2011 - Capt. Joel Santes initiated community kitchen to feed victims

- relief goods from both government and non-government and church-based sectors and concerned individuals arrived within the first 24-hours after the disaster

- medical stations were formed by the Barangay Committee on Health

\subsection{Leadership and engaged governance}

At the onset of the flashflood, the response team of the barangay and other agencies were not able to penetrate immediately the affected areas due to the forceful and risky current and height of the floodwaters. It was only when the water started to subside that responders were able to reach the affected areas.

The response measures provided by the different institutions, both government and private sectors, exemplifies the role of leadership and engaged governance gave the community the empowerment and support to self-organizing and attain its resiliency on the disaster. Interviews from key informants reveal that affected communities have shown participative and cooperative behavior towards government agencies in the response and recovery stages of the disaster incident, thus, highlighting their trust and confidence to the concerned agencies and its lead actors. 
INTERNATIONAL JOURNAL OF EDUCATIONAL MANAGEMENT AND

DEVELOPMENT STUDIES

Volume 1, Issue 1 • September 2020 • ISSN 2719-0633 (PRINT) 2719-0641 (ONLINE)

The immediacy of response, recovery and action of the different agencies and concerned organizations to assist the affected areas initially started six hours after the disaster. Figure 9 shows the timeframe of the disaster and post disaster activities, highlighting the role of different actors in disaster rescue and response.

\section{Figure 9}

Recovery and Response

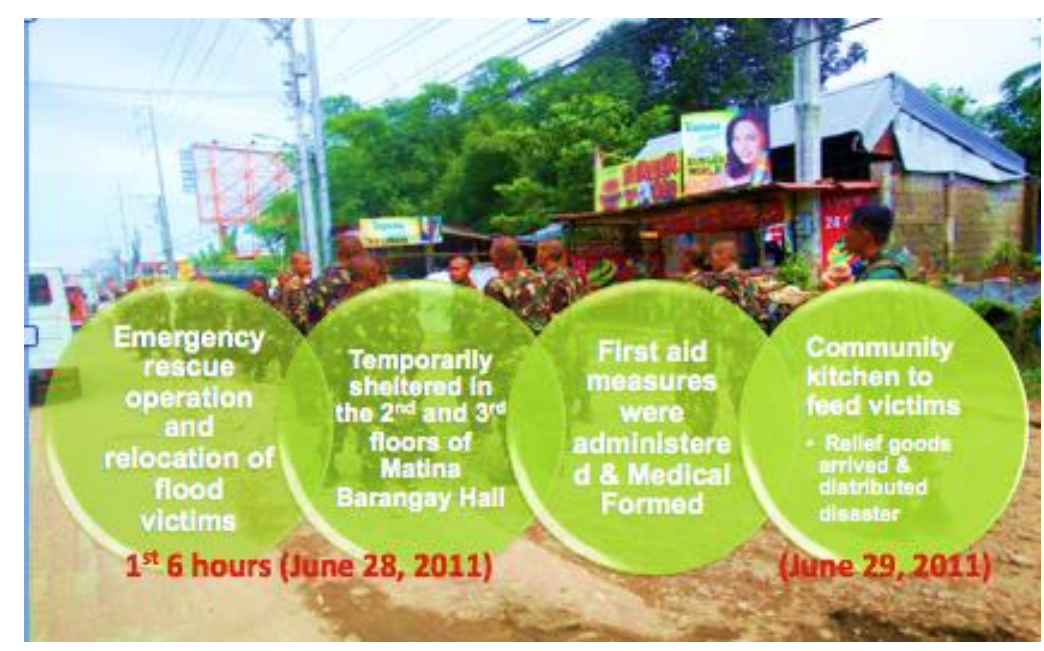

Various private organizations, concerned groups and NGOs, in addition to the government agencies were identified as responders of the disaster. These different institutions, including its specific human capital, have acted on the disaster as immediate as possible to provide response measures to the affected communities. As provided in figure 9, the specific actions and interventions of these institutions show that there is a very clear role of the elements of engaged governance, social networks and self-organizing as identified by the community resilience framework. However, despite the immediate response by various organizations and concerned groups, the disaster left some negative impact to the affected barangays and families. Table 2 shows the summary of the report of the disaster impact to the community.

In addition, 29 were recorded as casualties from drowning with more number of females than males and majority were children ages 8 months to 9 years old. This data shows the most vulnerable groups were the ones greatly affected by the disaster. Hence, the interaction of the hazard (flood) with the vulnerable group (children and women) in an unsafe condition resulted to disaster. 
INTERNATIONAL JOURNAL OF EDUCATIONAL MANAGEMENT AND

DEVELOPMENT STUDIES

Volume 1, Issue 1 • September 2020 • ISSN 2719-0633 (PRINT) 2719-0641 (ONLINE)

\section{Table 2}

Affected barangays and families

\begin{tabular}{lccc}
\hline \multicolumn{1}{c}{ Barangay } & Affected Areas & Affected Families & $\begin{array}{c}\text { \% to Total } \\
\text { Affected } \\
\text { Families }\end{array}$ \\
\hline Matina Crossing & 13 & 5,660 & $40.45 \%$ \\
Matina Pangi & 8 & 1,500 & $10.91 \%$ \\
Matina Aplaya & 13 & 1,304 & $9.49 \%$ \\
\hline $\begin{array}{l}\text { *Total \# of affected families in Davao City = 13,746 from 46 areas including two other } \\
\text { barangays, Talomo Proper and Maa (Source : NDRMC Siterep \#8, 3July2011) }\end{array}$ \\
\hline
\end{tabular}

The city government report, however, highlighted that despite this impact of the flashflood in the community, the social networks and the immediate response and action of the different institutions have provided the positive outlook among the people affected. They have come to realize that there was a concerted effort to minimize the impact and provide post-disaster assistance to help the communities recover from the incidence. However, there was no clear indication or observance of an inter-organizational coordination (Comfort \& Kapucu, 2006) during the process of the recovery phase.

\subsection{People-Place Relationships}

The city government documented that although Davao City experienced flooding when it rains, some contributory factors magnified the impact of the disaster. For one, it was observed that the heavy rainfall during the flashflood incident has accumulated more water at $60 \mathrm{~mm}$ during the unholy hours of $10 \mathrm{pm}$ to $1 \mathrm{am}$. This led to the delayed response among the residents of the affected communities. Incidentally, the upstream areas of Mintal and Calinan have expanded its agricultural activities as well as changes in production activities to meet the demands of an expanding population, thus, affected the ecology of the soil. This resulted to a faster outpour of the rain water towards the communities in the lower part of the area. Moreover, since the affected areas have been identified as an urbanized area, some of the riverbanks have been utilized as residential area due to the growing population, hence, decreasing the size of the waterways. The flowing water, ultimately, traversed into the road 
INTERNATIONAL JOURNAL OF EDUCATIONAL MANAGEMENT AND

DEVELOPMENT STUDIES

Volume 1, Issue 1 · September 2020 • ISSN 2719-0633 (PRINT) 2719-0641 (ONLINE)

networks. Similarly, as part of the city's expansion and development projects, siltation and sandbars have been observed to occupy some areas of the rivers, thus, creating the backflow of the Matina-Pangi river during high tide (Duterte, et al., 2016).

These factors were in consonance to the progression of vulnerability that interacted with the hazard (flood) that resulted into disaster. Thus, highlighting the people-place relationships as identified by the community resilience model.

The Post Disaster Management revealed that there is a need to prioritize the interplay of roles between the communities and the institutions, as well as, the integration of the basic transactional element of communication, cultural knowledge, values \& beliefs and the contextualization of these elements to adapt to the specific communities.

\subsection{Towards a New Theoretical Basis for Resilience Studies: the importance of culture and symbolism in Disaster Risk Reduction}

Alexander (2012) emphasized that human ecology posits a relationship between people and their environment in which technology can overcome some of the difficulties, but nature is not easily dominated and hence there must be adaptation to extremes. In the original work, the model shown in Figure 9 is based on the rational man who makes economic decisions as an optimizer, by maximizing opportunities to gather information, or a satisfier, by choosing rationally from a limited range of options. Evidently, this model allows no leg room for cultural or ideological variations and only the most limited opportunity for perception to govern choice. In reality, there is a constant dialectic between factors that increase risk (for example, stronger hurricanes, building new settlement in vulnerable areas, water management that increases downstream flood risk) and those that diminish it, the actions of disaster risk mitigation. Furthermore, he remarkably noted that few academic studies of disaster tackle the problem of culture being an assemblage of shared beliefs, opinions, social characteristics and attitudes. Thus, it is extremely difficult to measure in any social scientific way. Reason may be that it is an elusive and multi-faceted concept that changes with social context. In addition, culture as a set of nested phenomena, thus, we respond to different cultures related to national, regional and local settings; peer groups, families and workplaces; ethnic and social groups; gender and race; and interest groups. 


\section{INTERNATIONAL JOURNAL OF EDUCATIONAL MANAGEMENT AND DEVELOPMENT STUDIES}

Volume 1, Issue 1 · September 2020 • ISSN 2719-0633 (PRINT) 2719-0641 (ONLINE)

Moreover, culture undergoes a constant process of metamorphosis as it adapts to the changing circumstances of the modern world and how we are able to interpret it. As a result, there are very few reliable measures of culture. It is nonetheless highly important. If one wants to promote change, success is more likely if it is compatible with the prevailing culture, while if it runs against the culture, the adaptive process is likely to be blocked for apparently illogical reasons.

\section{Figure 11}

The architecture and metamorphosis of human culture

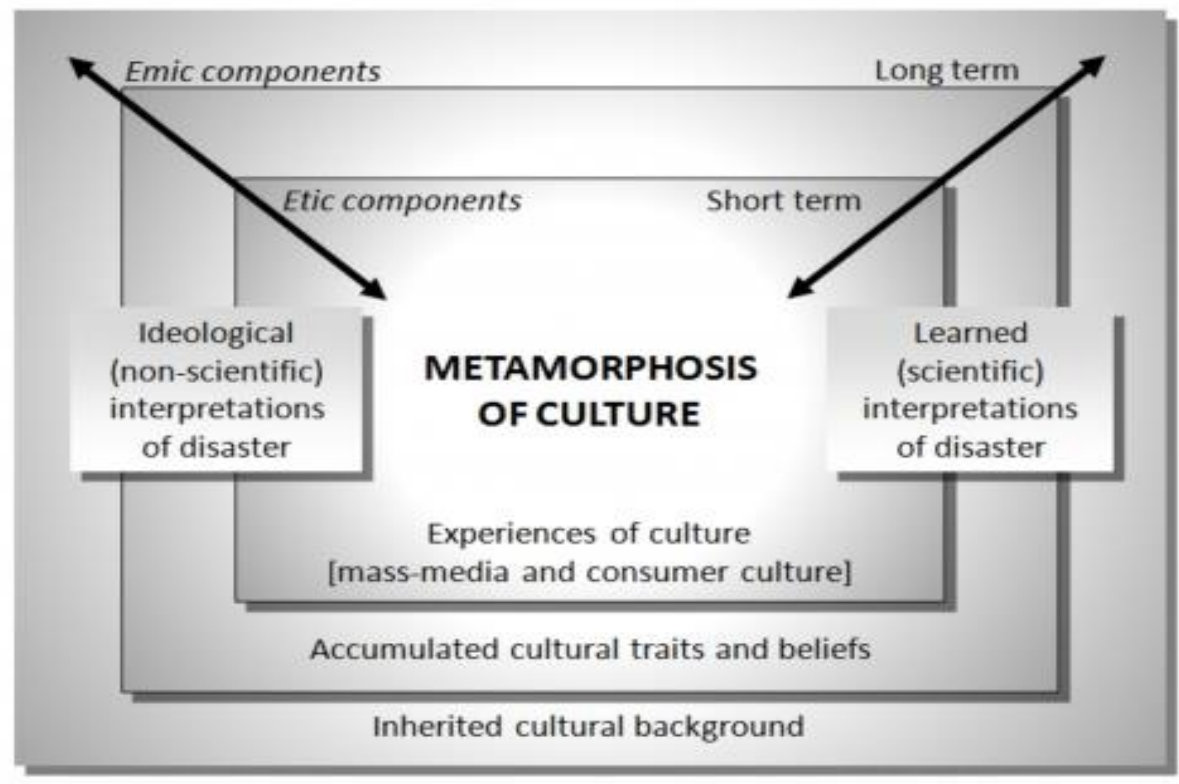

Source: Herbert Simon (1956)

Simon's model (Figure 11) shows that culture is dynamic, thus, a lot of factors can still be utilized to explain the relationships of man, environment and the institutions. These factors are important sources of cultural uniformity that would allow the community-based comprehension, appreciation and response to disaster situations. Hence, it encourages the idea that communities can help develop participative approaches in building "bottom-up" strategies for disaster resilience (O’Neill, 2004).

\subsection{Social Vulnerability to Disasters - the human-ecological approach}

Similarly, a social vulnerability model to disaster can be utilized for future disaster resilience studies that can further examine the relationship between man and environment 


\section{INTERNATIONAL JOURNAL OF EDUCATIONAL MANAGEMENT AND \\ DEVELOPMENT STUDIES}

Volume 1, Issue 1 • September 2020 • ISSN 2719-0633 (PRINT) 2719-0641 (ONLINE)

towards a human-ecological dimension. In the process, the Systems approach can better explain and show the inter-relationship and integration of man, environment and the institutions. Figure 10 shows that the existing approaches in disaster studies are linear, thus, fails to look at the human ecology aspect of the situation. Consequently, Alexander (2012) proposed the following model as alternative approach to the study of disaster resilience to address this gap in the area of disaster and resilience studies.

\section{Figure 12}

Possible evolution of models of disaster

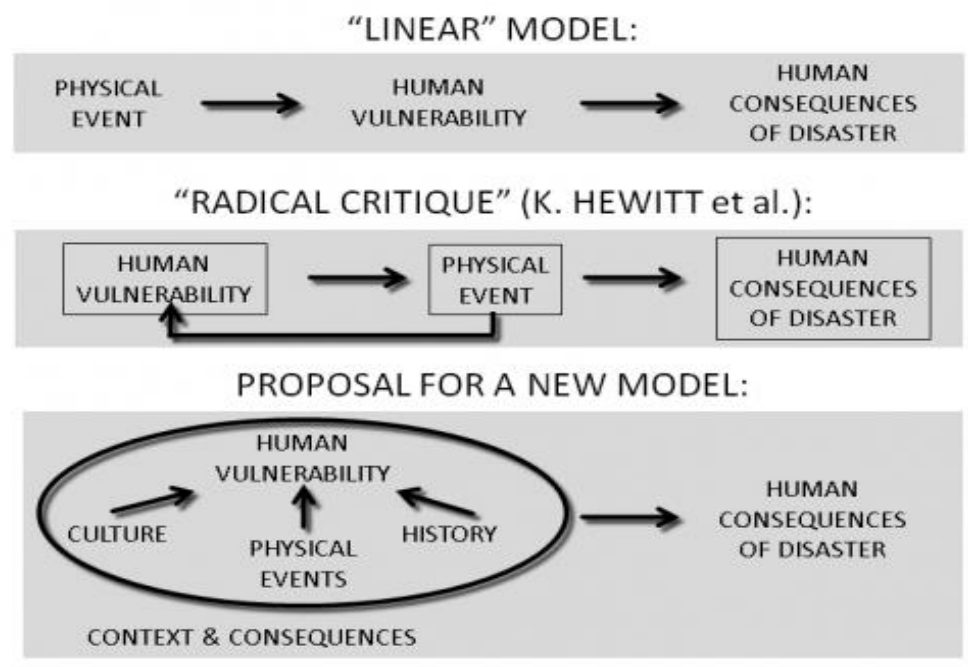

Source: Alexander (2012)

Figure 12 shows the possibility of evolution of human ecological models of disaster from a linear to a transactional approach, incorporating culture as part of the equation, thereby, contextualizing the study of disaster and its impact to humans and environment. Increasing knowledge of disasters and the social processes involved, and the complexity of life in the early 21 st century, suggest that a new model ought to be formulated (proposed model). The vulnerability of human socio-economic systems is acted upon by physical hazards (whether natural or anthropogenic), as well as cultural and historical factors. The plexus of the context and consequences of these associations is what determines the form, entity and size of any ensuing disaster (Alexander, 2012).

The analyses, insights and recommendations from this body of literature and case study would provide a more comprehensive view of the factors involved in disaster risk 
INTERNATIONAL JOURNAL OF EDUCATIONAL MANAGEMENT AND

DEVELOPMENT STUDIES

Volume 1, Issue 1 • September 2020 • ISSN 2719-0633 (PRINT) 2719-0641 (ONLINE)

studies. The major objective is to develop a risk communication management model that integrates the role of scientific, management and human-ecological component - considering the interplay of roles from the different perspectives.

\section{Conclusion}

Davao City is naturally a flood prone area. This is manifested by its physical characteristic where the entire land area of the city drains itself towards the Gulf Davao River and the Talomo River, the two rivers considered as the most important river basins in the city (Estacio 2013). The serious implication of this is magnified with the volume of population and human settlements found along the banks or nearby the river tributaries for example the housing, business and institutional areas affected by the Matina Flash Flood. However, the 2011 flash flood in Matina area exhibited a higher level of social capital among residents, various groups and institutions in Davao. The response was quickly mobilized. One of the advantages is that the City has highly sophisticated search and rescue personnel with facilities and equipment through its 911 . Their strength plus community mobilization made disaster response not only quick but effective as well. Although there are casualties recorded, mostly, vulnerable groups, i.e., women, children and senior citizens this is not as high compared to other areas with similar situation and given that the flood occurs without expectation and/or longer warning lead time. The Crunch Model is an effective tool in assessing vulnerabilities as it captures not only the factors and underlying issues that progresses/increases vulnerability among various groups but it also explores institutional and social capital dynamics.

Flooding in Davao City should not only be approached within the confines of Davao City geographical boundaries. It is multi-dynamics, and cross boundary issues. In this light, it is recommended for stakeholders to harmonize efforts and initiatives and find areas to work together given their varying interests - be it political, economic and environmental. It is also best to explore the ecosystem based and community-based adaptation measures. The latter will have significant contribution to building more resilient communities as it is 'a community-led process, based on communities' priorities, needs, knowledge and capacities, which should empower people to plan for and cope with the impacts of climate change' (Reid, 2015). Furthermore, it builds on human rights-based approaches to development that 
INTERNATIONAL JOURNAL OF EDUCATIONAL MANAGEMENT AND

DEVELOPMENT STUDIES

Volume 1, Issue 1 · September 2020 • ISSN 2719-0633 (PRINT) 2719-0641 (ONLINE)

target the most vulnerable people and fully includes them in all levels of adaptation planning and implementation. In recent years, CBA has shown that it can also operate at scale but with communities remaining central to planning and action, for example through mainstreaming into government processes.

But emphasis on areas to work on should be at the forefront of discussion and decision among key players, i.e., LGU, development-oriented group, etc. because according to Reid (2015), ecosystem-based adaptation (EbA) should (but does not always) have a strong community/participatory focus. Good community-based adaptation (CBA) should (but does not always) have a strong consideration of ecosystems and ecosystem services. This is where the real challenge in preparing communities for climate changes adaptation. However, long term perspective must be central to any development initiatives as far planning and development interventions to mitigate if not avoid flooding in Davao City, particularly in Matina area.

A critical prerequisite to effective disaster management is the minimization of related impacts through communication of risk information in a timely manner and in a format that all stakeholders can understand. Attaining this mandate can be a major challenge for disaster managers, especially in an increasingly globalized world characterized by higher levels of multi-culturalism as increasing numbers of people migrate to locations outside their culture-zones where, not only language differs, but also perceptions of and attitude towards hazard/disaster risk (Martin, 2003).

The challenge for disaster managers is therefore to design effective tools/strategies that not only span language differences, but also take into consideration cultural perceptions and attitudes so that the objectives of disaster risk-reduction can be achieved. Moreover, it is also best to explore the community based adaptation measures to building more resilient communities as it is 'a community-led process, based on communities' priorities, needs, knowledge and capacities, which should empower people to plan for and cope with the impacts of climate change' (Reid, 2015) and ultimately makes community more resilient to natural disasters and enable them to pursue dynamic future despite the challenges of these disasters. 
INTERNATIONAL JOURNAL OF EDUCATIONAL MANAGEMENT AND

DEVELOPMENT STUDIES

Volume 1, Issue 1 · September 2020 • ISSN 2719-0633 (PRINT) 2719-0641 (ONLINE)

\section{Acknowledgement}

The study was conducted as an exploratory part of the author's dissertation for the PhD Development Studies program under the supervision of Dr. Merlyne M. Paunlagui of the College of Public Affairs (CPAf), University of the Philippines, Los Banos, Laguna, Philippines.

\section{References}

Abramson, D., Stehling-Ariza, T., Park, Y., Walsh, L., \& Culp, D. (2010). Measuring Individual Disaster Recovery: A Socioecological Framework. Disaster Medicine and Public Health Preparedness,4(S1), S46-S54. doi:10.1001/dmp.2010.14

Alexander, David. (2012). Models of Social Vulnerability to Disaster. RCCS Annual Review. Issue No. 4, 2012.

Badri, S., Asgary, A., Eftekhari, A.R. \& Levy, J. (2006). Post Disaster Resettlement, Development and Change: A Case Study of the 1990 Manjil Earthquake in Iran. Disasters 30(4):pp451-468. Blackwell Publishing Oxford, UK. DOI: 10.1111/j.03613666.2006.00332.x.

Balang, Jr., A.D. (2010). Mainstreaming DRR in Barangays Apas, Bulacao and Kalunasan in Cebu City. In: by Leonore P. Dela Cruz, Elmer M. Ferrer, and Maureen C. Pagaduan. Building Disaster-Resilient Communities: Stories and Lessons from the Philippines. Quezon City, Philippines: CSWCD-UP.

Bene, C., Wood, R.G., Newsham, A. \& Davies, M. (2012). Resilience: New Utopia or New Tyranny? Reflection about the Potentials and Limits of the Concept of Resilience in Relation to Vulnerability Reduction Programmes. IDS Working Papers, Volume 2012, Issue 405. DOI: 10.1111/j.2040-0209.2012.00405.x.

Berkes, F., \& Ross, H. (2013). Community Resilience: Toward an Integrated Approach. Society \& Natural Resources, 26(1), 5-20. DOI: 10.1080/08941920.2012.736605.

Business World Online (n.d.). Available online at www.bworldonline.com. Accessed on May 2015. 
INTERNATIONAL JOURNAL OF EDUCATIONAL MANAGEMENT AND

DEVELOPMENT STUDIES

Volume 1, Issue 1 · September 2020 • ISSN 2719-0633 (PRINT) 2719-0641 (ONLINE)

Cacho, M.G. (2014). Negotiated Space As Arena Of Empowerment For Indigenous Communities In Bokod, Benguet, Philippines. UP Los Baños, PhD Community Development.

Cadag, J.R.D. \& Gaillard, J.C. (2012). Integrating Knowledge and Actions in Disaster Risk Reduction: The Contribution Of Participatory Mapping. AREA Vol 44 (1), 100-109. doi: 10.1111/j.1475-4762.2011.01065.x.

Comfort, L.K. \& Kapucu, N. (2006). Inter-Organizational Coordination In Extreme Events: The World Trade Center Attacks, September 11, 2001. Nat Hazards 39:309-327. DOI: https://doi.org/10.1007/s11069-006-0030-х

Cowles, E.R. (2015). Using the Social-Ecological Systems Framework to Evaluate Green Infrastructure: Coastal management case studies from Vietnam and Bangladesh. MS Paper in Science, Technology and Environmental Policy. University of Minnesota

Cramer, R.J. \& Kapusta, N.D. (2017). A Social-Ecological Framework of Theory, Assessment and Prevention of Suicide. Frontiers in Psycholology, 2017; 8: $1756 .$. https://doi.org/10.3389/fpsyg.2017.01756

David, Carlos Primo C. et. al. (2010). Community and DRR Technology Interface: the Reduction of Flood Risk in the Bicol River Basin II (BRB2). In: Leonore P. Dela Cruz, Elmer M. Ferrer, and Maureen C. Pagaduan. Building Disaster-Resilient Communities: Stories and Lessons from the Philippines. Quezon City, Philippines: CSWCD-UP.

Dela Cruz, L.P., Ferrer, E.M. \& Pagaduan, M.C. (2010). Building Disaster-Resilient Communities: Stories and Lessons from the Philippines. Quezon City, Philippines: CSWCD-UP.

Demeritt, D. \& Sebastien, N. (2014). Models Of Best Practice In Flood Risk Communication And Management. Environmental Hazards - Human and Policy Dimension, Vol 13 (4), pp.313-328.

Dodds, G.G. (2015). This Was No Act of God. Disaster, Causality and Politics. Risk, Hazard and Crisis in Public Policy, Vol. 6(1). 
INTERNATIONAL JOURNAL OF EDUCATIONAL MANAGEMENT AND

DEVELOPMENT STUDIES

Volume 1, Issue 1 • September 2020 • ISSN 2719-0633 (PRINT) 2719-0641 (ONLINE)

Duterte, J., Untalan, M. \& Casan, J. (2016). Personal Interviews. March 8, 2016.

Estacio, R.M. (2013). A Case Study Documenting the Various Methods Used by Local Barangay Unit of Matina Crossing in the Post-crisis Phase of the Davao City flashflood. Unpublished undergraduate thesis, UP Mindanao

Faulkner, L., K. Brown, and T. Quinn (2018). Analyzing Community Resilience As An Emergent Property Of Dynamic Social-Ecological Systems. Ecology and Society 23(1):24. https://doi.org/10.5751/ES-09784-230124

Furedi, F. (2007). The Changing Meaning of Disaster. Area Vol 39 (4), pp. 482-489.

Habito, C.F. (2009). Economy and Environment in the Philippines: Issues and Imperatives. In Habito, C. F. and S. Kojima (eds.), Mainstreaming Sustainable Development Policies in East Asia. ERIA Research Project Report 2008-6-2, Jakarta: ERIA.

Gall, M. (2013). From Social Vulnerability to Resilience: Measuring Progress toward DRR. InterSecTions 2013. UNU- EHS. No.13.

Garcia, A.T. (2010). Installing Early Warning System along the Agos River in the Municipalities of Infanta and General Nakar. In: Leonore P. Dela Cruz, Elmer M. Ferrer, and Maureen C. Pagaduan (eds). Building Disaster-Resilient Communities: Stories and Lessons from the Philippines. Quezon City, Philippines: CSWCD-UP.

Khan, H., Vasilescu, L. \& Khan, A. (2008). Disaster Management Cycle: A Theoretical Approach. Management and Marketing Journal, University of Craiova, Faculty of Economics and Business Administration, Vol. 6 (1), pages 43-50. https://ideas.repec.org/a/aio/manmar/v6y2008i1p43-50.html.

Kulkarni, V. \& Ramachandra, T.V. (2006). Environmental Management. New Delhi: TERI Press.

Lizarralde, G., Valladares, A., Olivera, A., Bornstein, L., Gould, K., \& Barenstein, J. D. (2015). A Systems Approach To Resilience In The Built Environment: The Case Of Cuba. Disasters, 39 Suppl 1, S76-S95. https://doi.org/10.1111/disa.12109 
INTERNATIONAL JOURNAL OF EDUCATIONAL MANAGEMENT AND

DEVELOPMENT STUDIES

Volume 1, Issue 1 · September 2020 • ISSN 2719-0633 (PRINT) 2719-0641 (ONLINE)

Magalang, M.R. (2010). Mainstreaming DRR and CCA in Mandatory Planning and Budgeting Processes of Barangays: A Case Study on Building Disaster-resilient Communities in Marinduque”. In: Leonore P. Dela Cruz, Elmer M. Ferrer, and Maureen C. Pagaduan (eds). Building Disaster-Resilient Communities: Stories and Lessons from the Philippines. Quezon City, Philippines: CSWCD-UP.

Martin, F. LaTanya (2003). Cultural Differences in Risk Perception: An Examination of USA and Ghanaian Perception of Risk Communication. MSc. Thesis. Virginia Polytechnic Institute and State University.

Mercado, R. (2016). People's Risk Perceptions and Responses to Climate Change and Natural Disasters in BASECO Compound, Manila, Philippines. Procedia Environmental Sciences. 34. 490-505. 10.1016/j.proenv.2016.04.043.

Mercer, J. (2010). Disaster Risk Reduction Or Climate Change Adaptation: Are We Reinventing The Wheel? Journal of International Development 22(2). https://doi.org/10.1002/jid.1677

Mochizuki, J., Mechler, R., Hochrainer-Stigler, S., Keating, A., \& Williges, K. (2014). Revisiting The 'Disaster And Development' Debate - Toward A Broader Understanding Of Macroeconomic Risk And Resilience. Climate risk management, 3, 39-54. https://doi.org/10.1016/j.crm.2014.05.002

National Disaster Risk Reduction Management Council (NDRRMC) Site Rep, 03 July 2011. Available online at: http://www.ndrrmc.gov.ph/attachments/article/1347/Final_Report_on_the_Effects_an d_Emergency_Management_re_Tropical_Storm_SENDONG_(WASHI)_Status_of_E arly_Recovery_Programs_in_Region_X_issued_10FEB2014.pdf.

National Disaster Risk Reduction Management Council (NDRRMP) Manual 2011-2028. 2011. Available online at: http://www.ndrrmc.gov.ph/attachments/article/41/NDRRM_Plan_2011-2028.pdf. 
INTERNATIONAL JOURNAL OF EDUCATIONAL MANAGEMENT AND

DEVELOPMENT STUDIES

Volume 1, Issue 1 · September 2020 • ISSN 2719-0633 (PRINT) 2719-0641 (ONLINE)

O’Brien, G., O’Keefe, P., Rose, J. \& Wisner, B. (2006). Climate Change And Disaster $\begin{array}{llll}\text { Management. } & \text { Disasters } & \text { 30(1): 64-80. DOI: }\end{array}$ https://onlinelibrary.wiley.com/doi/abs/10.1111/j.1467-9523.2006.00307.x.

Office of the City Planning and Development, Davao City (no date). Information Manual.

O’Neill, P. (2014). Developing a Risk Communication Model to encourage community safety from natural hazards. State Emergency Service. Available online at: http://citeseerx.ist.psu.edu/viewdoc/download?doi.10.1.1.466.108

Olson, R.S. \& Gawronski, V.T. (2010). From Disaster Event to Political Crisis: $A$ '5C+A' Framework for Analysis. International Studies Perspectives 11, 205-221. DOI: 10.1111/j.1528-3585.2010.00404.x

Ramachandra, TV, Utam Kumar \& Bharath H. Aithal. (2012). Ecological Approach for Mitigation of Urban Flood risks. Ecosystem Approach to Disaster Risk Reduction. Edited by Anil K. Gupta and Sreeja S. Nair. National Institute of Disaster Management (NIDM), New Delhi, India.

Reid, H. (2015). Ecosystem and Community-Based Adaptation: Learning from communityBased Natural Resource Management. Climate and Development. DOI: $10.1080 / 17565529.2015 .1034233$

Reynolds, B. \& Seeger, M. (2005). Crisis and Emergency Risk Communication as an Integrative Model. Journal of Health Communication. Vol 10(1), 43-55.

Romolini, M., Bixler, R.P., \& Grove, J.M. (2016). A Social-Ecological Framework For Urban Stewardship Network Research To Promote Sustainable And Resilient Cities. Sustainability. 8(10): 956. http://dx.doi.org/10.3390/su8090956 [15 p.].

Sammadar, Subhajyoti, Yokomatsu, Muneta, Dayour, Frederick, Oteng-Ababio, Martin, Dzivenu, Togbiga, Adams, Mujeeb and Ishikawa, Hirohiko. (2015). Evaluating Effective Public Participation In Disaster Management And Climate Change Adaptation : Insights From Northern Ghana Through A User-Based Approach. Risks, Hazards \& Crisis in Public Policy, Vol 6(1). DOI:10.1002/rhc3.12075. 
INTERNATIONAL JOURNAL OF EDUCATIONAL MANAGEMENT AND

DEVELOPMENT STUDIES

Volume 1, Issue 1 · September 2020 • ISSN 2719-0633 (PRINT) 2719-0641 (ONLINE)

Sanchez, K.M. (2014). IEC Strategies on Risk Management and Precautionary Practices of

Residents in Barangay Matina Crossing 74-A. Unpublished undergraduate thesis, UP Mindanao.

Sanchez, K.M. \& Sumaylo, D.J.F. (2015). IEC Strategies on Risk Management and other Precautionary Practices of Residents in Barangay Matina Crossing 74-A. Paper presented at the International Conference on Communication/Culture and the Sustainable Development Goals (CCSDG): Challenges for a New Generation, Chiang Mai, Thailand. Conference Proceedings. Retrieved from http://rcsd.soc.cmu.ac.th/web/CCSDG/home.php

Stephenson, R.S. (1994). Disasters and Development. 2nd ed. UNDP Disaster Management Training Module.

Stephenson, R.S. \& DuFrane, C. (2002a). Disasters and Development: Part I. Relationships between Disasters and Development.” Prehosp Disaster Med. 2002; 17(2):110-115. doi:10.1017/s1049023x00000273.

Stephenson, R.S. \& DuFrane, C. (2002b). Disasters and Development: Part 2: Understanding and Exploiting Disaster-Development Linkages. Prehosp Disaster Med. 2002;17(3):170-175. doi:10.1017/s1049023x00000418.

Stokols, D., Lejano, R.P. \& Hipp, J. (2013). Enhancing The Resilience Of HumanEnvironment Systems: A Social-Ecological Perspective. Ecology and Society 18(1): 7. http://dx.doi.org/10.5751/ES-05301-180107.

Sudhira, H.S., Ramachandra, T.V. and Jagadish, Kaup. (2013). Urban Sprawl Pattern Recognition And Modeling Using GIS. Map India Conference.

Tselios, V. \& Tompkins, E. (2017). Local Government, Political Decentralization And Resilience To Natural Hazard Associated Disasters. Environmental Hazards: Vol 16 (3), 228- 252. DOI: 10.1080/17477891.2016.1277967.

United Nations Development Program (UNDP) (1991). Human Development Report 1991, United Nations e-lib. New York, NY. https://doi.org/10.18356/d67a40a5-en. 
INTERNATIONAL JOURNAL OF EDUCATIONAL MANAGEMENT AND

\section{DEVELOPMENT STUDIES}

Volume 1, Issue 1 • September 2020 • ISSN 2719-0633 (PRINT) 2719-0641 (ONLINE)

United Nations International Society for Disaster Reduction (UNISDR) (2007). Links

between Vulnerability and Risk Reduction, Development and Climate Change: A Briefing for Sweden's Commission on Climate Change and Development. Retrieved from: https://www.unisdr.org/files/8383_pbdisasterriskreduction1.pdf

United Nations. (2001). Human Development Report 2001. Making New Technologies Work for Human Development. Retrieved from: http://hdr.undp.org/sites/default/files/reports/262/hdr_2001_en.pdf

United Nations (2005). The Millennium Development Goals Report. New York, NY. Retrieved from: https://unstats.un.org/unsd/mi/pdf/MDG\%20Book.pdf

United Nations. (2015). The Millenium Development Goals Report. New York, NY. Retrieved from: https://www.un.org/millenniumgoals/2015_MDG_Report/pdf/MDG\%202015\%20rev $\% 20(J u l y \% 201) . p d f$

Villanueva, D. \& Aid, C. (2010). Building Disaster-Resilient Communities: Stories and Lessons from the Philippines. In: Leonore P. Dela Cruz, Elmer M. Ferrer, and Maureen C. Pagaduan (eds). Quezon City, Philippines: CSWCD-UP.

Wisner, B., Gaillard, J.C. \& Kelman, I. (2012). Framing Disaster: Theories and Stories Seeking to Understand Hazards, Vulnerability and Risk. Handbook of Hazards and Disaster Risk Reduction. 18-34.

World Bank. (2012). The World Bank Annual Report 2012. Volume 1. Washington, DC. 